\title{
PREVALENCE OF THE BURNOUT SYNDROME AMONG BRAZILIAN MEDICAL ONCOLOGISTS
}

\author{
Joáo Glasberg, louise Horiuti, Marcela Araújo Borges Novais, Andressa Zaccaro Canavezzi, Vanessa da Costa Miranda, Felipe Abrosio Chicoli, \\ Marina Sahade Gonçalves, Carolina Games Bensi, Auro del Giglio*
}

Fundação Faculdade de Medicina do ABC, Santo André, São Paulo, Brazil

\author{
*Correspondence: \\ Divisão de Hematologia e \\ Oncologia, Fundação \\ Faculdade de Medicina ABC \\ Rua Mariana Correia, 369 \\ São Paulo/SP, Brasil \\ Cep: 01444-000 \\ Tel/fax: (+55 11) 3819-5007 \\ sandrabr@netpoint.com.br
}

\begin{abstract}
SUMMARY
INTRODUCTION. Burnout syndrome which is prevalent among oncologists is characterized by three aspects: emotional exhaustion, depersonalization and low personal accomplishment. The purpose was to evaluate prevalence of the burnout syndrome among Brazilian medical oncologists and the variables that correlate with its presence.

Methods. A survey was conducted with members of the Brazilian Society of Medical Oncology (SBOC) who received three questionnaires (general, Maslach burnout questionnaire and an opinion survey) mailed to all 458 members.

Results. Response rate was of 22.3\%. According to the criteria proposed by Grunfeld, which consider burnout present when at least one of the aspects is severely abnormal, prevalence of this syndrome was $68.6 \%$ (95\% confidence interval, Cl: $58.68 \%$ to $77.45 \%$ ). By multivariate analysis having a hobby/physical activity, a religious affiliation, older age, living with a companion and rating vacation time as sufficient were correlated significantly and independently with burnout syndrome. Conclusions. The burnout syndrome is prevalent among Brazilian oncologists. Oncologists having sufficient personal and social resources to engage in a hobby, physical activity, have enough vacation time and religious activities are at lower risk of developing burnout.
\end{abstract}

KEY wORDS: Professional burnout. Medical oncology. Affective symptoms. Religion. Stress.

\section{INTRODUCTION}

Burnout, viewed as the exhaustion of physical or emotional strength as a result of prolonged stress was recognized in the 1970s, and has been detected in a wide variety of health care providers. Characterized by three basic aspects: emotional exhaustion (EE), depersonalization (DP), low personal accomplishment (PA)', the burnout syndrome must be identified early to prevent depersonalization of the provider-patient relationship ${ }^{2}$. Furthermore, the burnout syndrome may often cause symptoms that can adversely affect the quality of life of the health care professionals involved such as anxiety, irritability, mood swings, insomnia, a feeling of failure, depression, and drug addiction 2.3 . Significantly, this syndrome may be also associated with a reduction in job performance and stress related health problems ${ }^{4}$. The burnout syndrome is therefore an occupational disease of the health care professional that must be recognized early and treated.

This syndrome is also prevalent among medical oncologists. Indeed, Whippen et al. in 1991 surveyed members of the American Society of Clinical Oncology (ASCO) and reported that $56 \%$ of them met the criteria for burnout syndrome ${ }^{5}$. Whippen reported that frustration or a feeling of failure was the preferred description of burnout by the surveyed oncologists, whereas insufficient personal and/ or vacation time was the most frequent reason chosen to explain the existence of this syndrome. Additionally, administering palliative or terminal care, reimbursement issues, and a heavy work load were identified as contributing factors to burnout, according to these authors.

In this study a similar survey conducted among members of the Sociedade Brasileira de Oncologia Clínica (SBOC) is reported in an effort to estimate the rate of burnout among Brazilian medical oncologists and the variables that may be associated with this syndrome.

\section{Methods}

A general questionnaire, an opinion survey and the Maslasch Burnout Inventory (MBI) was mailed to all 458 members of the SBOC. Members were invited to anonymously answer all questionnaires. Reply, as was explained in the accompanying cover letter, was considered to be an agreement to participate in the survey. Answered questionnaires were received from November 2004 to June, 2005. An attempt was made to increase the number of replies by an e-mail remainder to all members during the aforementioned period. This study was approved by both the Institutional Review Board and by the president of SBOC.

The general questionnaire included questions regarding age, gender, marital status, number of children, place of work where most of the professional time was spent (public/teaching institution, private office, etc), subspecialty, number of patients seen daily, time devoted to see a new patient or a follow-up visit, amount of time dedicated to patient care, physical activity, vacation 
GLASBerg | et AL.

time (and if this time was considered sufficient), if there was a hobby and if the oncologist reported having a religion. All oncologists were also directly asked if they would again choose medical oncology as a career.

The MBl is a 22 item questionnaire that surveys all three dimensions of the burnout syndrome (EE, DP, PA) and provides scores for these dimensions as previously described ${ }^{6}$, thereby allowing each to be classified as severely, moderately or minimally affected, according to the scoring system of the MBI questionnaire. The MBI used was in the portuguese language 7 . Since the crude scores for EE, DP and PA provided by the $\mathrm{MBI}$ are difficult to interpret, the criteria proposed by Ramirez et al. ${ }^{8}$ and Grunfeld et al. ${ }^{9}$ were used to diagnose the presence or absence of burnout syndrome. According to the Ramirez criteria, burnout syndrome is present when all three dimensions are severely abnormal whereas according to the criteria proposed by Grunfeld, burnout is present when at least one aspect is severely abnorma 18,9 .

The medical oncologists were also surveyed on their opinion about what they rated the most important seven out of 14 proposals presented to reduce or avoid burnout syndrome. Proposals included decreasing the number of patients seen daily, increasing the time allotted to see each patient, less paperwork, etc.

In order to evaluate correlations between categorical variables Fisher and Chi square tests were used. To evaluate correlations between continuous and categorical variables the analysis of variance (ANOVA) test was employed. Logistical regression was used to conduct multivariate analysis, having the presence of burnout according to either Ramirez or Grunfeld criteria as a dependent variable and other variables whose $p$ value at univariate analysis was lower than 0.10 , such as choosing oncology as a career again, having a religious affiliation a hobby/physical activity, etc as independent variables. For statistical calculations the NCSS 2000-PASS 2000 (Utah, EUA) computer software, was utilized.

\section{RESULTS}

Of the 458 questionnaires mailed, 102 were returned (22.3\% response rate). Mean age was 43.1 years, $64.4 \%$ of the respondents were male, $91.17 \%$ were married, $95.04 \%$ lived with a companion and $82.3 \%$ had children. Most of the respondents were medical oncologists $(97 \%)$ and the majority worked in more than one place: 58 (56.9\%) of them worked in a public institution, $64(62.7 \%)$ at private institutions, 29 (28.4\%) had teaching appointments, 81 (79.4\%) worked in a private office and $3(2.9 \%)$ were retired. Most of the oncologists (51 . I\%) spent the greatest part of their time at their private office and this was also the preferred place to work for $52.5 \%$. Interestingly, when the place where oncologists spent the greatest number of hours working was correlated with their preferred place of practice, there was a $75 \%$ concordance rate. Seventy two (70.58\%) of the surveyed oncologists reported that they had a religious affiliation (Tables I and 2).

About half of those surveyed (52.47\%) worked more than 50 hours a week. Most of them spent 30 minutes to one hour with a new patient and 15 to 30 minutes with a follow-up visit. In terms of patients seen per day, $51 \%$ saw up to $15,25 \%$ saw from 16 to 20 and $24 \%$, more than 20 patients a day. Most of the surveyed oncologists

\begin{tabular}{lcc}
\hline \multicolumn{3}{c}{ Table I - Demographic characteristics of the oncologists who } \\
replied to the survey
\end{tabular}

reported that they received family support (92. 15\%), had a religious affiliation (70.58\%), regularly performed physical activity and/or had a hobby $(65.34 \%)$. The majority of participants took vacations regularly (88.23\%): 34 (33.3\%) took up to I5 days, whereas 56 (54.9\%) of them took more than I 5 days per year. Most of the respondents $(62.74 \%)$ felt that their vacation time was insufficient. When asked if they would choose oncology as a career again, 90 (88.25\%) answered affirmatively (Tables I and 2).

Results and interpretations of the MBI according to Grunfeld and Ramirez are depicted in (Table 3) According to the Ramirez criteria, which consider burnout syndrome present when all three dimensions are severely abnormal, prevalence of the burnout was 7.8\% (95\% confidence interval, $\mathrm{Cl}: 3.44 \%$ to $14.87 \%$ ). By Grunfeld criteria that consider burnout present when at least one aspect is severely abnormal, prevalence of this syndrome was $68.6 \%$ (95\% Cl: 58.68\% to $77.45 \%$ ).

According to the criteria of Grunfeld et al. burnout correlated significantly with living with a companion $(p=0.0064)$, rating vacation time as insufficient $(p=0.0047)$ and not having a hobby/physical activity 


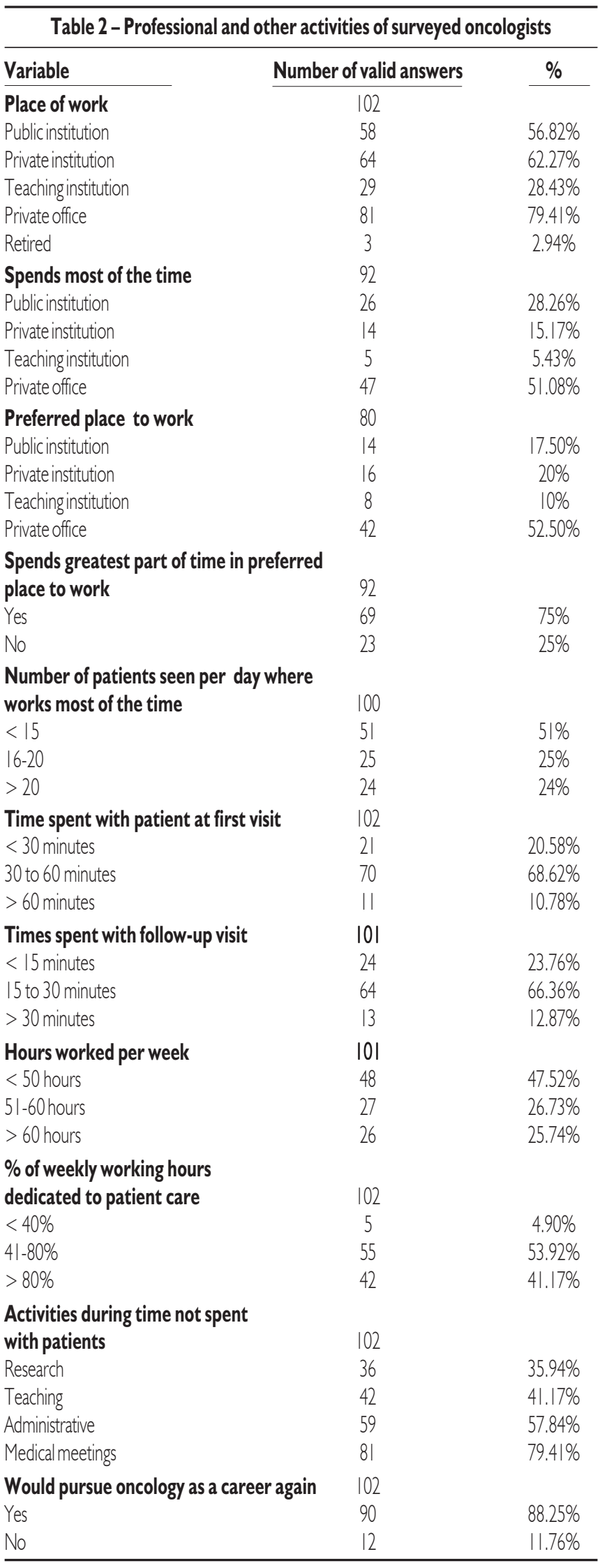

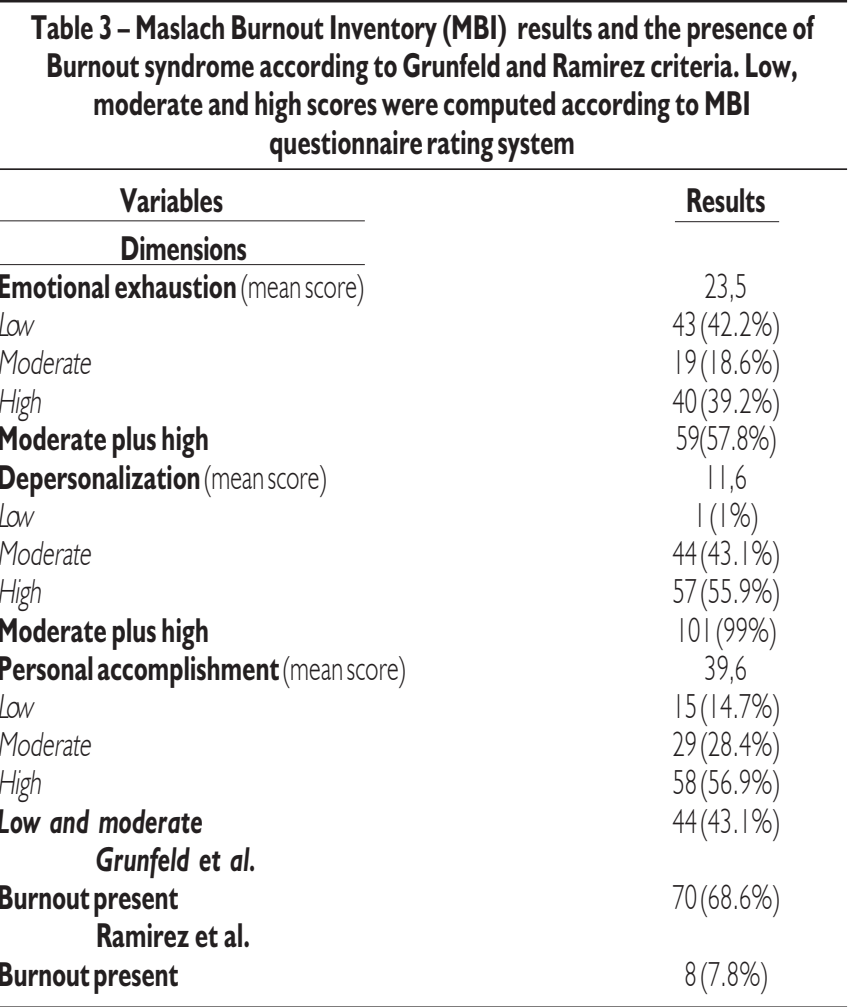

$(p=0.0221)$. In terms of the criteria proposed by Ramirez et al. presence of burnout was significantly correlated with not having a hobby/physical activity $(p=0.0009)$ and not having a religious affiliation ( $p=0.0364)$. It was further perceived that oncologists who were classified as burnouts by Ramirez criteria were significantly younger than those who did not present burnout (43.73 \pm 0.9245 vs $35.87 \pm$ 3. 1352; $p=0.018)$. It is noteworthy that there was a positive and significant correlation between burnout syndrome and unwillingness to choose oncology as a career again, both by Ramirez $(p=0.0133)$ and Grunfeld ( $p=0.026$ ) criteria. According to either Ramirez or Grunfeld criteria, no statistically significant correlations were observed between burnout and the number of patients seen or the time oncologists spent with them.

Multivariate analysis was conducted by logistic regression and showed that living with a companion ( $p=0.017$ ), having a hobby and/ or regular physical activity $(0.052)$ and rating vacation time as sufficient $(p=0.018)$ according to Grunfeld criteria remained significant for burnout. However, according to Ramirez criteria, only having a hobby and/or regular physical activity $(p=0.01 \mathrm{I})$, age (0.042) and having a religious affiliation $(0.038)$ remained significant independent variables for burnout.

The opinion questionnaire revealed that most of the surveyed oncologists rated limiting the numbers of patients seen daily (85.3\%), less paperwork, (83.3\%), better relationship with insurance companies (63.7\%), higher financial gains (61.8\%) and personal growth potential in their job (54.9\%), as the most important measures to prevent burnout. 
GLASBerg | et AL.

\section{Discussion}

The burnout syndrome commonly affects health professionals and medical oncologists also frequently suffer from this syndrome $e^{1,2,3,5}$. The very demanding tasks of dealing with acutely ill patients and their families, a great deal of bureaucracy and the emotional issues relating to death and palliative care are some of the challenges faced daily by medical oncologists, which may predispose them to the burnout syndrome. The dire consequences of this syndrome for the health and quality of life of those affected ${ }^{2,4}$, as well as the adverse impact on their professional performance together with a high prevalence in other countries $^{5}$ was a motivation to survey Brazilian medical oncologists to estimate its prevalence and search for potentially preventable factors.

The inverse correlation of religious affiliation with burnout had been previously reported by Kash et al. who also reported a statistically lower rate of the burnout syndrome among religious oncologists ${ }^{10}$. Likewise, the high $88.2 \%$ rate of an affirmative response to the question whether oncology would be chosen again as a career, is in agreement with the data of Barni et al. ${ }^{1 \prime}$ and Whipen et al. ${ }^{5}$. The importance of sufficient vacation time found in the survey was also reported in the Whippen et al. study where $57 \%$ of the medical oncologists rated enough vacation time as the most important measure to avoid burnout ${ }^{5}$. In a follow-up survey ${ }^{12}$ conducted 10 years after the first ${ }^{5}$. Whipen et al reported a $36 \%$ rate of burnout and that about half of the oncologists who participated in the survey still thought that more vacation time would help to decrease burnout.

The finding that living with a companion correlated positively with burnout according to Grunfeld criteria is an unexpected finding for which there was no adequate explanation. However, since all married oncologists reported living with their spouses, it is unlikely that a high frequency of low marriage satisfaction could be present at the time of the study. However, one may surmise that emotional stress at home with a companion may also contribute to burnout. Interestingly, since there are no reliable data in the literature that describe the rates of marriage satisfaction and/or divorce among medical oncologists, this may be a rewarding subject for future research. Otherwise, it is possible that since there are very few unmarried oncologists, most of the burnout happened among married individuals. Since most oncologists were married (91. 17\%), the small variance of this variable might account for a statistical artifact that might complicate interpretation of these correlations.

As mentioned, having a hobby and/or engaging in a physical activity, rating vacation time as sufficient and having a religious affiliation correlated inversely and significantly with the presence of burnout. Therefore, it is believed that oncologists disposing of sufficient personal and social resources to engage in a hobby or physical activity, to have enough vacation time and religious activities are at lower risk of developing burnout.

However, since some of these factors, such as increasing vacation time, engaging in physical activity and having a hobby are subject to change, it is possible that this syndrome may be potentially preventable by stimulating oncologists to adjust their schedules to include more time to pursue these activities. Nevertheless, it is recognized that the factors considered as subject to change, especially adjusting the schedule and increasing personal vacation time, may not be easily accomplished in view of the growing economic pressure and time constraints in health care worldwide.

The main limitation of this study was the rather low response rate of $22.3 \%$ raising questions about true representativity of results. Nevertheless it was found that according to the Ramirez criteria, prevalence of burnout was $7.8 \%$ ( $95 \%$ Cl: $3.44 \%$ to $14.87 \%$ ) and according to the criteria proposed by Grunfeld, prevalence of this syndrome was $68.6 \%$ (95\% Cl: $58.68 \%$ to $77.45 \%)$ These results are in agreement with a previous survey of medical oncologists conducted in the USA which showed a rate of burnout of $56 \%{ }^{5}$. A similar survey had also been conducted among members of the Brazilian cancer society ${ }^{13}$. In that study response rate was $21 \%$ and all three dimensions were affected at moderate or severe levels (Ramirez Criteria) in 15.7\% of the surveyed participant physicians.

It is concluded that burnout syndrome is prevalent among Brazilian oncologists. Oncologists disposing of sufficient personal and social resources to engage in a hobby or physical activity, to have enough vacation time and religious affiliation are at lower risk of developing burnout syndrome.

\section{No conflict of interest}

\section{Resumo}

INTRODUÇÃo. A Síndrome da Estafa Profissional (SEP) é considerada uma doença caracterizada por três componentes básicos: exaustão emocional (EE), despersonalização (DP) e reduzida realização pessoal $(R P)$, sendo identificada em oncologistas.

OBIETIVO. Analisar a prevalência da SEP entre oncologistas clínicos e possíveisfatores relacionados.

MÉtodos. Foram enviados três questionários (Questionário Geral, Questionário Maslach de Burnout e Questionário de Opinião) para 458 cancerologistas cadastradosnaSociedade Brasileirade Oncologia Clínica(SBOC).

RESULTADOS. Ataxa de respostafoide 20\%. 43,3\% dos entrevistados demonstraram nível baixo de EE, 57,8\% apresentaram nivel alto de DP e 55,5\% alta RP. Para avaliarmos a presença da SEP, utilizamos o critério de Ramirez, que considera as três dimensões em nível grave (8,9\%) e o de Grunfeld que considera pelo menos um dos três domínios em nível grave (68,9\%). Pelos critérios de Ramirez, houve correlação negativa com praticar exercícios/hobby $(p=0,0007)$ e crer em uma religião $(p=0,0445)$ com SEP. Já por Grunfeld, se correlacionou positivamente com morar com o companheiro $(p=0,0054)$ e considerar o tempo de férias insuficiente $(p=0,0037)$. Por ambos os critérios, foi constatada uma correlação positiva entre ter a síndrome e não optar por oncologia novamente se tivesse essa oportunidade.

CONCLUSÃo. A SEP é muito prevalente entre os oncologistas clínicos. Porém, a maioria destes profissionais optaria novamente por essa especialidade. Prática de exercícios/hobby, tempo de férias suficiente e crer em uma religião surgiram como possíveis fatores para prevenir esta síndrome. [Rev Assoc Med Bras 2007; 53(I): 85-9]

Unitermos: Estafa profissional. Oncologia. Síndrome. Despersonalização. 


\section{RefERences}

I. Felton JS. Burnout as a clinical entity - its importance in health care workers. Occup Med (Lond). 1998;48(4):237-50.

2. Shanafelt TD, Bradley KA, Wipf JE, Back AL. Burnout and self-reported patient care in an internal medicine residency program. Ann Intern Med. 2002; | 36(5):358-67.

3. Gundersen L. Physician burnout. Ann Intern Med. 200 । ; 35(2): | 45-8.

4. Parker PA, Kulik JA. Burnout, self-and supervisor-rated job performance, and absenteeism among nurses. J Behav Med. 1995; I 8(6):58 I-99.

5. Whippen DA, Canellos GP. Burnout syndrome in the practice of oncology: results of a random of 1,000 oncologists. J Clin Oncol. 1991;9(10): 1916-20.

6. Maslach C, Schaufeli WB, Leiter MP. Job burnout. Annu Rev Psychol. 2001;52:397-422.

7. Silveira NM, Vasconcellos SJL, Cruz LP, Kiles RF, Silva TR, Castilhos DG, et al. Assessment of burnout levels in a sample of police officers. Rev Psiquiatr Rio Gd Sul. 2005;27(2): I 59-63.

8. Ramirez AJ, Graham J, Richards MA, Cull A, Gregory WM, Leaning MS, Snashall DC. Burnout and psychiatric disorder among cancer clinicians. $\mathrm{Br}$ J Cancer. | 995;7|(6): | 263-9.

9. Grunfeld E, Whelan TJ, Zitzelberger L, Willan AR, Montesanto B, Evans WK. Cancer care workers in Ontario: prevalence of burnout, job stress and satisfaction. CMAJ. 2000; I 63(2): I 66-9.
10. Kash KM, Holland JC, Breitbart W, Berenson S, Dougherty J, OuelletteKobasa S, ET AL. Stress and burnout in oncology. Oncology (Huntingt).2000; | 4( I I): I 62 I-33; discussion I 633-4, I 636-7.

I I. Barni S, Mondin R, Nazzani R, Archili C. Oncostress: evaluation of burnout in Lombardy. Tumori. 1996;82( I):85-92.

12. Whippen DA, Zuckerman EL, Andersen JW, Kamin DY, Holland JC. Burnout in the practice of oncology: results of a follow-up survey. J Clin Oncol. 2004;22(Suppl | 4):6053.

13. Tucunduva LT, Garcia AP, Prudente FV, Centofanti G, de Souza CM, Monteiro TA, et al. Incidence of the burnout syndrome among Brazilian cancer physicians. Rev Assoc Med Bras. 2006;52(2): I08- 12.

Artigo recebido: 15/1 1/06 Aceito para publicação: 04//2/06 